\title{
Industrial- or Residential-Dominant Development? A Comparative Analysis of Maritime Industrial Development Areas of Liaoning, China
}

\author{
Fei Chen ${ }^{1}$, Sherry $\mathrm{Yu}^{2}$, Lianlian Liu ${ }^{1}$, Wei Lu ${ }^{1} \& \mathrm{Jun} \mathrm{Cai}^{1}$ \\ ${ }^{1}$ Dalian University of Technology, Dalian, Liaoning, China \\ ${ }^{2}$ Division of Social Sciences, New College of Florida, Sarasota, FL, USA \\ Correspondence: Sherry Yu, Division of Social Sciences, New College of Florida, Sarasota, FL, 34243, USA. Tel: \\ 1-941-487-4207. E-mail: syu@ncf.edu
}

The Second Correspondence: Wei Lu, Dalian University of Technology, Dalian, Liaoning, China. E-mail: luwei_dut@msn.com

Received: February 19, 2019

Accepted: March 19, 2019

Online Published: March 30, 2019

doi:10.5539/jsd.v12n2p82

URL: https://doi.org/10.5539/jsd.v12n2p82

\begin{abstract}
This paper adopts a case-comparison method to study the spatial layout features of maritime industrial development areas (MIDAs) in Liaoning, China, in reference to similar projects in other Asian countries including Japan, South Korea and Singapore. Our study focuses on industry-city spatial relationship, land position and proportion, coastline utilization intensity and industrial land organization. We show that supplementary residential and recreational land has primarily occupied the high-quality coastlines, and resulted in limited industrial access to marine resources. Our theoretical and empirical analyses connect this feature to local government finances, purchase restriction policy and an investment-driven surge in demand for coastal residential housing. Many areas now exhibit low utilization of industrial land accompanied by the emergence of "ghost cities" phenomenon, which are critical factors that the policymakers should consider in the future planning of coastal development. Interviews with local developers, housing authority personnel, relocated employees and residents confirm our findings. We conclude with policy recommendations for promoting long-term sustainable development in the coastal area.
\end{abstract}

Keywords: coastal industrial area, coastline utilization, MIDA, land supply, ecosystem

\section{Introduction}

\subsection{Overview}

China is endowed with abundant marine resources and has recently oriented towards coastal industrial development to facilitate international trade through marine shipping ${ }^{1}$. Substantial national planning has been set in place for the establishment of maritime industrial development areas (MIDAs) and supplementary residential areas in the province of Liaoning, utilizing the natural coastal advantage of Bohai Bay and existing heavy-industrial production base. Nonetheless, large-scale construction and relocation of industrial plants to MIDAs revealed serious planning deficiencies and subsequently led to low production efficiency, poor resource utilization and surplus supply of residential housing. Liaoning's GDP has contracted by $11.4 \%$ in 2016 compared to China's national average growth of $6.9 \%$, ranking the lowest among all provinces and autonomous cities. This paper unfolds the spatial planning deficiencies in theoretical and qualitative perspectives, and empirically assesses the contributing role of local governments in shaping Liaoning's coastal developmental patterns.

We first adopt a case-comparison method to closely examine Liaoning's MIDAs relative to other projects in neighboring countries of Japan, South Korea and Singapore. Spatial layout features are comparatively assessed with respect to industry-city spatial relationship, land position and proportion, coastline utilization intensity and industrial land organization. We find that the supplementary residential and recreational land has primarily occupied the high-quality coastlines, and limited the industrial access to marine resources.

To further examine on why Liaoning's MIDAs has turned into luxury residential development, we proceed with 
theoretical and empirical analyses. Using the planner's problem, we first identify prominent conflict and challenges in the projects' development goals, with focus on the lack of planning for long-term sustainability and emerging public health concerns. Many areas now exhibit low utilization of industrial land accompanied by "ghost cities" phenomenon, which are critical factors that policymakers should consider in the future planning of coastal development. We further explore the economic incentive of local governments and identify an interconnection between regional land development and economic policies, government finances and real estate market in Liaoning, China. Our results reveal a causal relationship between real estate investment and local government fiscal revenue, which would reorient industrial expansion to luxury residential development. We conclude with policy suggestions to central planners aimed to enhance economic efficiency and promote sustainable development in the long-run.

\subsection{Historical and Socioeconomic Background}

In the past decade, the Chinese government has issued a series of economic and industrial policies to promote marine resource utilization and resulted in the expansion and relocation of numerous industrial plants to coastal areas $^{2}$. To provide accommodation for relocated employees, residential towns have been developed near the plants intended to provide convenient access to local services, schools and other essential needs.

Situated in the northeastern region of China, Liaoning has traditionally been a pillar province for heavy industrial production. Petrochemical, mining, machine and equipment manufacturing form its main production base. Liaoning possesses large deposits of iron ore and crude oil, and is a leading producer of natural gas, oil and steel in China. Nonetheless, this province has recently suffered from significant economic contractions possibly due to the combination of the 2008 global recession, low commodity prices and rampant corruptions. Since 1978, China has adopted an open-door policy and focused on producing labor-intensive goods to promote export growth. The accession to the World Trade Organization (WTO) in 2001 has further promoted the expansion of light manufacturing industries, whereas traditional heavy industries have become less prominent in driving China's economic growth. Figure 1 shows Liaoning's GDP and GDP growth with visible declining trends.

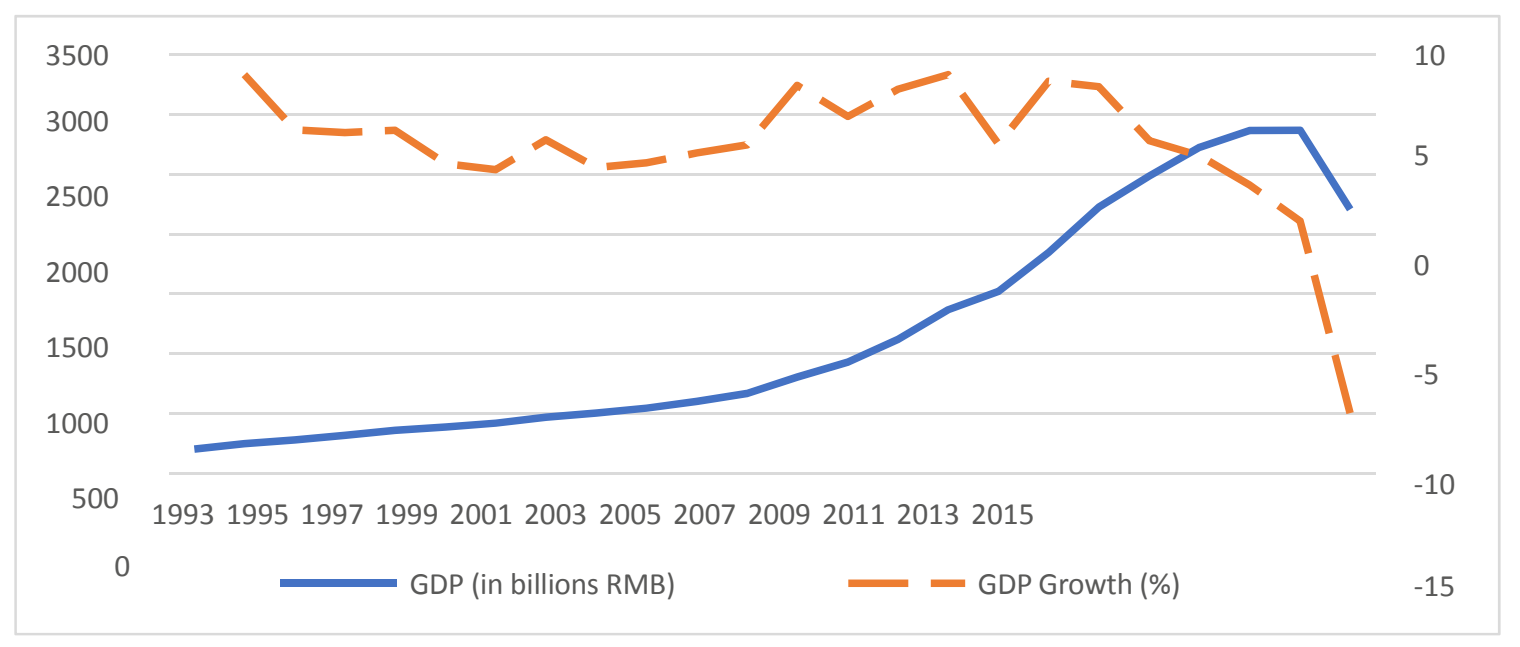

Figure 1. GDP and GDP growth of Liaoning, China from 1993 to 2016

Note. Data is obtained from Liaoning Statistical Yearbook (1993 to 2015) and CEInet Statistics Database.

Despite economic downturns, cargo throughput of Liaoning's ports has shown significant growth over the past decade. Liaoning has a geographical advantage over other inland provinces in northern China by occupying more than $35 \%$ of the Bohai Bay coastlines. Shipping ports in Liaoning have shown steady growth in container volume, primarily servicing trade between China and neighboring countries including Russia, Japan, North Korea and South Korea. Port of Dalian is the second largest container transshipment hub in Mainland China and ranked as the $7^{\text {th }}$ busiest container port in 2016 by handling more than 9.58 million TEU (twenty-foot equivalent units). It also possesses the world's largest crude oil terminal, and is responsible for processing all foreign-traded vehicles in northeastern China. Port of Yingkou ranked the $9^{\text {th }}$ busiest port in China with more than 6 million TEU in 2016. Liaoning serves as a critical hub that facilitates trade in the Pacific Rim and provides essential support to foreign trade of raw materials and heavy industrial output. Song et al. (2017) document the steady growth of shipping port lengths and volume in Liaoning since 2005 as the result of the aforementioned economic 
policies that promoted coastal development. Figure 2a depicts the annual port throughput in China and Liaoning from 2000 to 2014, with average annual growth rates of $5.62 \%$ and $6.29 \%$, respectively. Figure $2 \mathrm{~b}$ shows the trend of growth in port length in Liaoning and its selected cities. Liaoning's coastline has grown from $1885 \mathrm{~km}$ in 2000 to $2447 \mathrm{~km}$ in 2014, mostly through land reclamation and massive construction of new shipping ports (Ma et al., 2014).

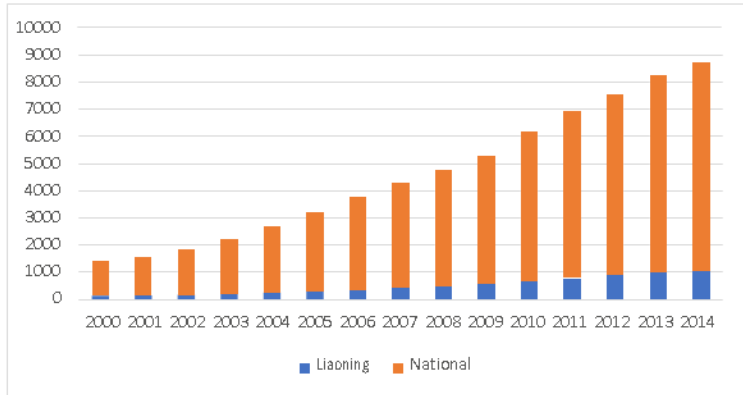

Figure 2a. Annual port throughput 2000-2014.

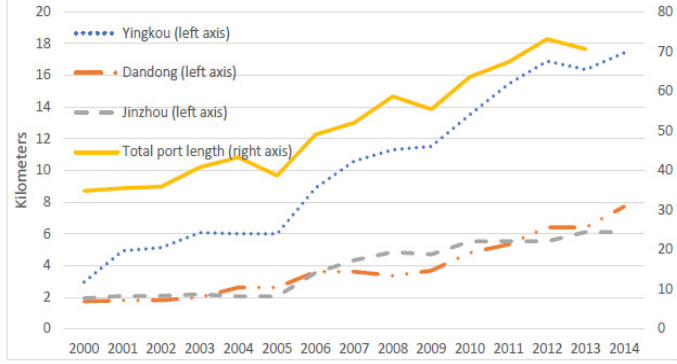

Figure 2b. Port length (km) 2000-2014

Note. Data is obtained from Liaoning Statistical Yearbook (1999 to 2015).

The Twelfth-Five Year Planning of China has budgeted more than RMB 90 billion of investment to facilitate the construction and development of shipping ports in Liaoning. The cities of Panjin, Yingkou, Huludao, Dalian and Jinzhou all have central plans for the creation and expansion of massive shipping ports that could potentially accelerate Liaoning's economic growth through trade. The number of quay berths has more than doubled since 2000. Relocating industrial plants to coastal cities aimed at better utilization of shipping ports seem compatible with economic incentives, but why has Liaoning's industrial production continued to decline in recent years? This paper examines the planning features and land use patterns of Liaoning's MIDAs in close detail to infer about their economic viability and sustainability in the long-run.

\subsection{Literature Review}

This paper is related to three strands of literature. The first explores various forms of urbanization, and the role of MIDAs and marine economy in driving economic growth. MIDAs first emerged in Western Europe and Japan in the 1950s and 1960s, aimed at providing a spatial integration of land-sea production and transportation system $^{3}$. Wang et al. (2017) argue that the effectiveness of MIDAs is highly sensitive to government policies and global economic conditions. Robinson (1985), Todd and Hsueh (1990) and Sonn (2005) present case studies of South Korea's heavy industrial complexes and find that central planning and support of local government agencies are essential to the success of MIDAs. Our paper complements these works by investigating the specific spatial features of selected East Asian MIDAs and closely examine Liaoning's projects within the context of China's economic transitions. MIDAs in China are more broadly connected to urbanization and provide an anchor point to study regional development disparities. Empirical researchers find that rapid industrialization and urbanization of eastern coastal areas in China is closely connected to the growth of international trade and substantial transformation of rural farm land (Zhang et al., 2016, Mody and Wang, 1997, Chen and Feng, 2000, and Liu, 2007). Han and Yan (1999) provide an overview of China's coastal cities development strategies and conclude that China faces a series of challenges in finding appropriate balance between economic growth and sustainability in resource use. Wang et al. (2014) find that coastal wetland area has been reduced by over 50\% in recent decades, with significant loss of biodiversity and destruction of natural habitats, with Bohai Bay being one of the most critically affected regions experiencing an increasing demand for large-scale reclamation. Song et al. (2017) further question the long-term strategic planning of MIDAs in Liaoning with serious concerns over the presence of large state-owned enterprises, lack of sufficient research and development, slow technology growth, shrinking population and unbalanced industrial expansion.

Another important strand of literature studies urban land governance and land politics in the context of China. The central question of study is how land politics have shaped China's land markets and transformed municipal governments as major market actors with the control of revenue from urban development (Hsing, 2006 and 2010). The author finds that real estate development generated a significant amount of land profits and increased the urban-rural tension in property rights. Another debate in this literature centers on how China's decentralization is counterbalanced by the rise of state control in urban land governance, along with real-estate 
driven urbanization and the emergence of "ghost cities". Xu and Yeh (2009), Wu et al. (2007), He and Wu (2005), Liu et al. (2012) and Zhang (2014) are examples of leading work in this strand of literature. Ding (2003), Lichtenberg and Ding (2009) and Lin and Yi (2011) find that local government revenue significantly increased after financing major infrastructure projects and public goods, but has also led to greater social inequality, conflict and government corruptive behavior. The resulted real-estate driven over-development is directly related to the emerging phenomenon of "ghost cities" in China. Previous research suggests that land-centered urbanization with market speculation, weak economic fundamentals and rapid credit expansion are the leading factors ${ }^{4}$. Nonetheless, researches have not yet provided evidence on the direct linkage between industrial and residential planning for newly established towns, and overlook the effect of inefficient planning on land-use distortions. Our paper is the first to examine the recent coastal industrial land development policy and its impact on local real estate market and government land finances.

In light of increasing tension between the government and land consumers in regards to rising concerns over regional disparity, environmental destruction and economic prosperity, we also study the theoretical implication of the planner's problem pioneered by Campbell (1996) and Campbell (2016). We examine the current points of conflict and challenges China's central planners may experience in promoting coastal industrial growth. Our extended theory identifies the unresolved conflicts between economic development, social justice, public health and environmental protection, and provides policy recommendations to promote modern, balanced, sustainable industrial towns in coastal Liaoning.

\section{Land Use Patterns in Japan, South Korea, Singapore and Liaoning, China}

This section analyzes the planning deficiency and ineffective use of coastal land in Liaoning's MIDAs in reference to other comparable projects. The development of MIDAs around the world can be divided into two types: a) expansion of existing ports to better integrate the industrial-transportation system (examples include Rotterdam, Antwerp, and Kaohsiung); and b) the creation of new industrial land along the coast followed by the development of residential and supportive service land (most commonly seen in Japan, South Korea and Singapore ${ }^{5}$ ). Liaoning's MIDAs also fit in to the second type with newly established industrial clusters situated away from established urban areas. We choose cases from Japan, South Korea and Singapore based on three factors: 1) they are neighboring countries that have tight trade relationships with China; 2) they share similar development background to cases in Liaoning; and 3) Liaoning focuses on the production and trade of heavy industrial goods, and many coastal development projects from these countries also involve primarily the production, manufacturing and trade of heavy metal and petrochemical goods.

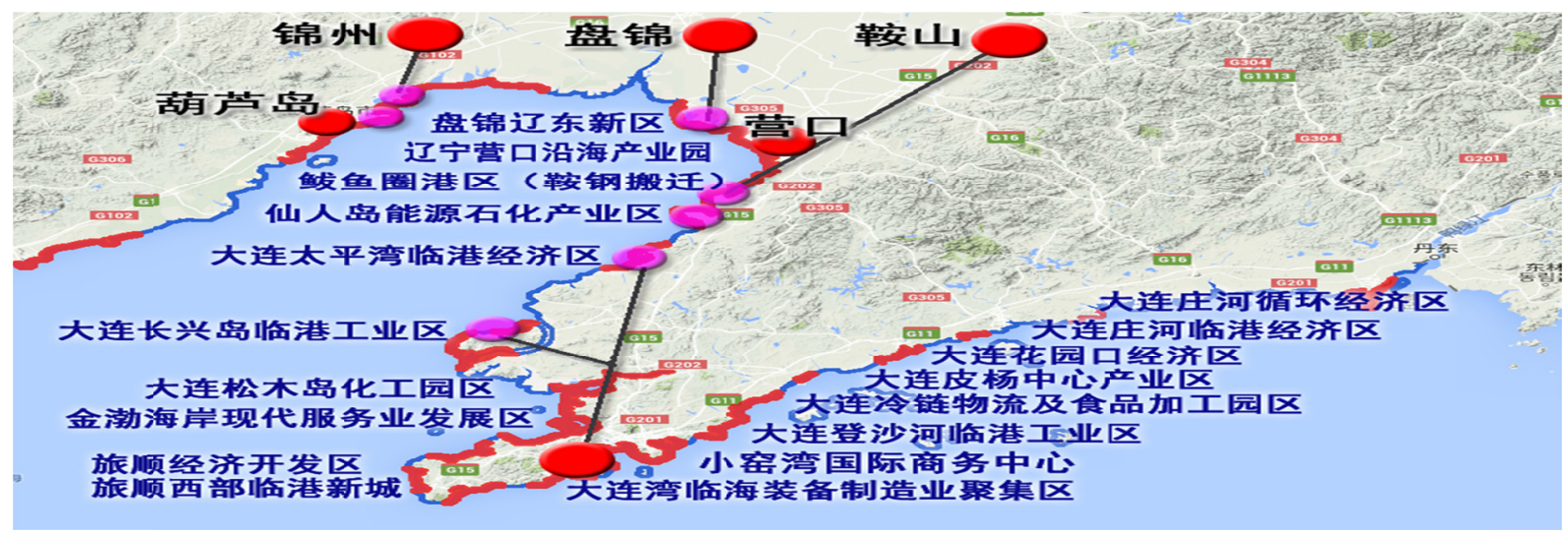

Figure 3. Coastal industrial development areas in the Bohai Bay

Note. The red dots indicate established cities, the pink dots illustrate coastal industrial plants and the red lines depict coastlines that are already developed or under development. Data is obtained using GoogleEarth and Liaoning Statistical Yearbook (1999-2015).

The projects under study include: Japan's Keiyo, Mizushima, Kashima, Yokkaichi, Wakayama, Oita, and Harima, South Korea's Pohang and Singapore's Jurong Island. We use GoogleEarth to study the spatial layout features of these industrial development projects, identify and analyze their common characteristics in terms of strategic planning and land use, and focus on the key differences of Liaoning's MIDAs in reference to these projects. 


\subsection{Land Coverage}

The geographical location of all MIDAs under study is notably away from metropolises. Figure 3 plots the major development areas established since 2011 with many situate far away from city centers. The red dots indicate established cities, the pink dots illustrate coastal industrial plants and the red lines depict coastlines that are developed or under development. Nonetheless, the land coverage of Liaoning's MIDAs appears to be massive compared to other cases.

The city of Pohang in South Korea covers a landmass of $68.4 \mathrm{~km}^{2}$, and the land area of Pohang Industrial Zone and Port of Pohang combined is about $16 \mathrm{~km}^{2}$. In Singapore, Jurong island forms a total area of about $32 \mathrm{~km}^{2}$ including areas from land reclamation. Most of Japan's coastal industrial zones span less than $20 \mathrm{~km}^{2}$ except for Keihin and Keiyo with land areas of 43 and $60 \mathrm{~km}^{2}$, respectively. Table 1 lists some of the major coastal industrial areas in Japan with an average land coverage of $16.61 \mathrm{~km}^{2}$.

Table 1. Landmass of major coastal industrial areas in Japan

\begin{tabular}{llcc}
\hline \multicolumn{1}{c}{ Prefecture } & Location of Coastal Industrial Areas & Total Landmass $\left(\mathbf{k m}^{2}\right)$ & Average Landmass $\left(\mathbf{k m}^{\mathbf{2}}\right)$ \\
\hline Aichi-ken & Chita, Kinuura, Toyohashi, Tahara & 62.29 & 15.57 \\
Osaka & Osaka, Sakai Semboku, Hannan & 48.94 & 16.31 \\
Hyogo-ken & Himeji, Kakogawa, Kobe, Amagasaki & 79.78 & 19.95 \\
Kanagawa-ken & Tokyo, Kawasaki, Yokohama, Negishi & 70.78 & 17.70 \\
Fukuoka-ken & Kitakyushu, Hakata, Kanda & 60.54 & 20.18 \\
Hiroshima-ken & Otake, Hiroshima, Fukuyama & 26.42 & 8.81 \\
Chiba-ken & Chiba, Kimitsu & 58.98 & 29.49 \\
Okayama-ken & Mizushima, Kasaoka & 25.71 & 12.86 \\
Ibaraki-ken & Kashima, Onahama, Hitachi Port & 33.16 & 11.05 \\
Mie-ken & Yokkaichi & 16.96 & 16.96 \\
Oita-ken & Oita, Beppu & 14.75 & 7.38 \\
\hline Total & & 498.31 & 16.61 \\
\hline
\end{tabular}

Note. Official data realeased by Department of Transportation of Japan and our own calculation using GoogleEarth is used to compile the table.

Table 2. Overview of new large-scale coastal industrial areas in Liaoning

\begin{tabular}{|c|c|c|c|c|}
\hline Municipality & Coastal Industrial Areas & $\begin{array}{c}\text { Distance from City Center } \\
(\mathbf{k m})\end{array}$ & $\begin{array}{l}\text { Land Coverage } \\
\qquad\left(\mathrm{km}^{2}\right)\end{array}$ & Leading Industry \\
\hline Jinzhou & Jinzhou Coastal Economic Area & 20 & 161 & Mechanical \\
\hline Panjin & Liaodong Bay New Area & 40 & 306 & Petrochemical \\
\hline Yingkou & Bayuquan Economic and Technological Area & 50 & 268 & Iron and steel \\
\hline Yingkou & Xianren Island Energy and Chemical Area & 60 & 159 & Petrochemical \\
\hline Dalian & Taiping Port Economic Area & 100 & 275 & Logistics \\
\hline Dalian & Changxing Island Coastal Industrial Area & 90 & 349.5 & Petrochemical \\
\hline Dalian & Dalian Pine Island Chemical Industrial Area & 68 & 35 & Petrochemical \\
\hline Dalian & Dengshahe Port Industrial Area & 70 & 50.6 & Iron and steel \\
\hline Dalian & Huayuankou Coastal Industrial Area & 110 & 34.5 & Biological \\
\hline Average & & 67.56 & 182.07 & \\
\hline
\end{tabular}

Note. Data is obtained from Statistical Yearbook of Dalian, Yingkou, Panjin and Jinzhou (2005-2015). 
The newly developed MIDAs in Liaoning have substantial landmass. Table 2 provides an overview of the scale of recent major development projects in coastal Liaoning. For the nine projects understudy, landmass varies from $34.5 \mathrm{~km}^{2}$ to $349.5 \mathrm{~km}^{2}$, with a mean and median of $182.1 \mathrm{~km}^{2}$ and $161 \mathrm{~km}^{2}$, respectively. Large-scale land reclamation in some areas is necessary to provide the desired land coverage. For example, the Liaodong Bay New Area (developed under the city of Panjin) occupies a total area of $306 \mathrm{~km}^{2}$ including $120 \mathrm{~km}^{2}$ from land reclamation, which is about 4 times the landmass of Jurong Island. The Changxing Island Coastal Industrial Area (developed under the city of Dalian) is consisted of five individual islands with a total landmass of $349.5 \mathrm{~km}^{2}$, significantly greater than any of the coastal development areas in Japan, South Korea and Singapore.

\subsection{Land Development and Planning}

Despite individual characteristics, most MIDAs in Japan, South Korea and Singapore exhibit industrial-dominant development features including closely integrated shipping ports and industrial plants organized in clusters. In contrast, Liaoning's MIDAs show a strong residential-dominant land use pattern with limited utilization of marine resources planned for industrial plants. Figure $4 \mathrm{a}$ to Figure $4 \mathrm{~g}$ illustrate the land use patterns of seven comparable MIDAs from Japan. Shipping ports are centrally located and surrounded by industrial plants, leading to a highly integrated land planning that minimizes local transportation costs, reduces inventory holding and production cycle, and increases the overall operation turnover.

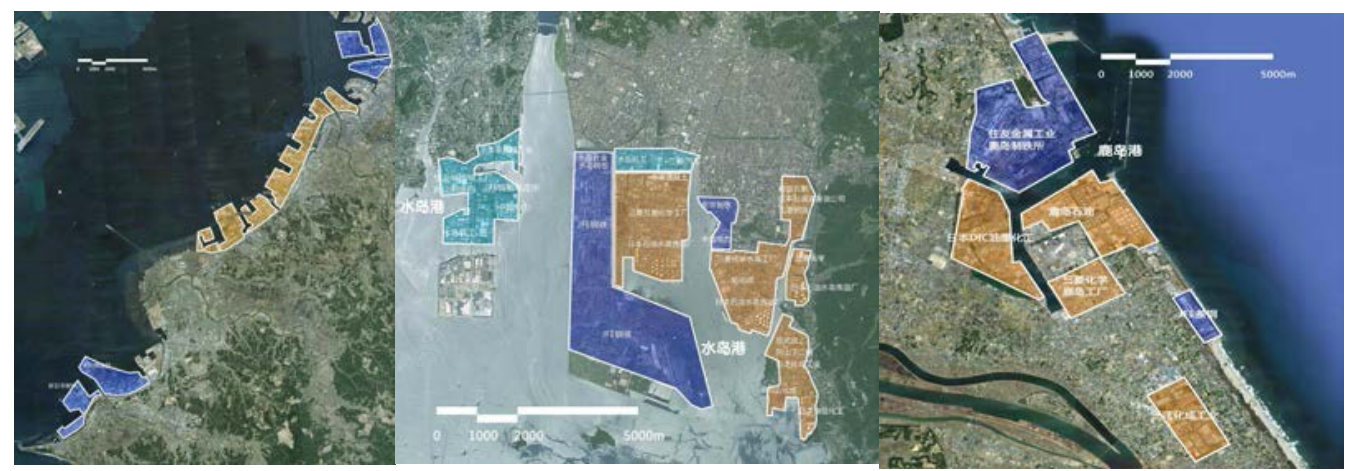

a. Keiyo

b. Mizushima

c. Kashima

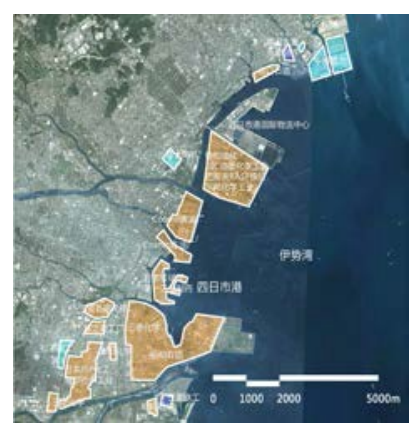

d. Yokkaichi

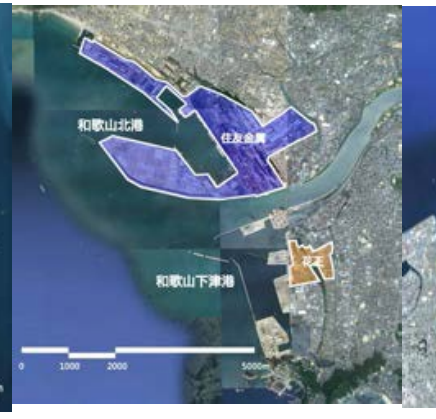

e. Wakayama

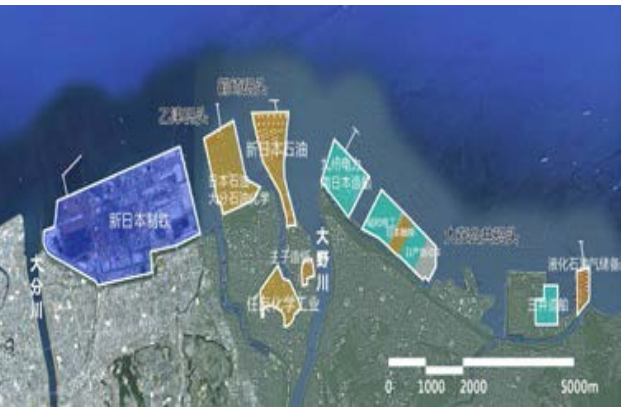

f. Oita

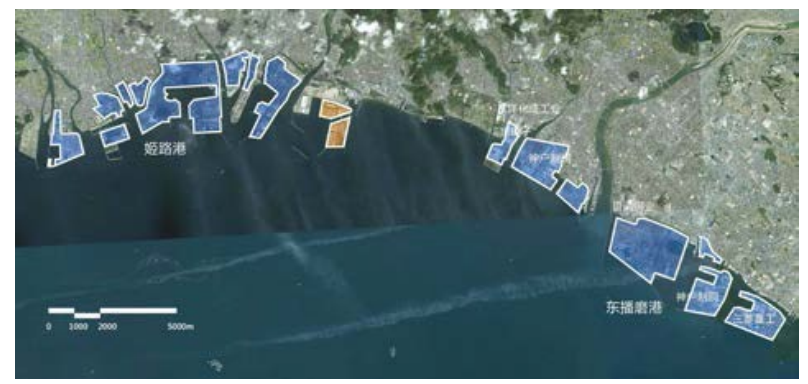

g. Harima

Figure 4. Land distributions of selected coastal industrial development areas in Japan

Note. Yellow shaded areas represent petrochemical plants, blue shaded areas represent iron-steel production 
plants and the cyan shaded areas represent machine/equipment manufacture plants. Data is obtained from GoogleEarth and manually labelled by the authors.

As shown in Figure 5a, Pohang appears to be distinctive as the port primarily services only one company (POSCO). The port is located as part of the iron and steel production plants, with no visible divide between them. In contrast, the Jurong industrial estate in Singapore is geographically separated from the mainland, and also includes many smaller islands and reclaimed land scattered around (see Figure 5b). Four large shipping ports have been created through land reclamation that have significantly increased the port length and are centrally located to closely integrate with surrounding production plants. Green spaces have been created to connect different islands and provide the ecological foundation of the industrial estate.

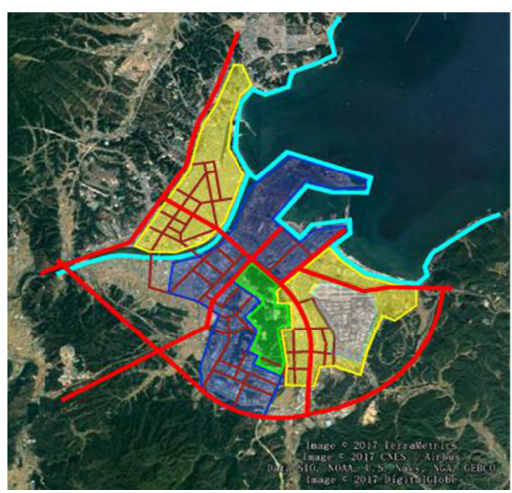

a. Pohang

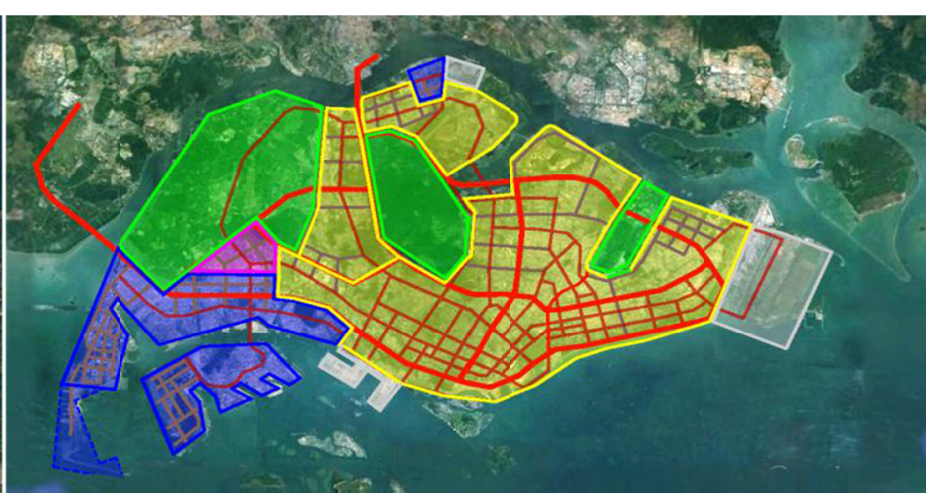

b. Jurong Island

Figure 5. Land distributions of Pohang and Jurong Island

Note. Yellow shaded areas represent residential development, blue shaded areas represent industrial development, green shaded areas represent greenspace, and grey shaded ares represent shipping ports and airports. Data is obtained from GoogleEarth and manually labelled by the authors.

Cluster-design of production plants is a common feature in these MIDAs. The Puhang port is designed to support the iron and steel production clusters adjacently located, and Jurong Island is home to more than 100 multi-national companies that operate in the chemical and petrochemical clusters. Similar development areas in Japan show greater efficiency in maximizing industrial output while minimizing land size. For example, the Keiyo industrial area hosts four major oil and gas production plants and five petrochemical industrial complexes. With landmass of around $60 \mathrm{~km}^{2}$, Keiyo produced 2.5 million tonnes of Ethylene in 2009, accounting for more than $30 \%$ of Japan's national production. Five thermal power plants have been constructed to provide electricity to sustain large-scale production.

Liaoning's MIDAs appear highly distinctive of the cases in Japan, South Korea and Singapore. Figure 6a to 6e illustrate the distribution of industrial-commercial-residential land for five major areas, with clear disconnection between industrial plants and shipping ports. Residential land is shaded in yellow, red areas represent commercial and service land, industrial plants are highlighted in brown, and shipping ports are illustrated in grey. Residential-dominance is evident as housing properties occupy prime coastal locations and some have pushed industrial plants inland with little or no access to oceanfront (Figure $6 \mathrm{a}, \mathrm{b}$ and c). Some coastal industrial areas are not equipped with shipping ports (Figures $6 \mathrm{a}, \mathrm{b}$ ) or have ports located a significant distance away from major production facilities (Figure $6 \mathrm{c}$ ). Some areas use land reclamation to create luxury coastal living areas and geographically segregate industrial production and coastal resources (Figures $6 \mathrm{~b}, \mathrm{~d}$ and e). Industrial plants also appear to be separated by residential or service land, lacking any cluster-design to promote economies of scale. The original intent of coastal industrial development was to effectively use marine resources to facilitate transport and trade of industrial goods and increase production efficiency. Nonetheless, our study shows that in many cases, urban planning and land use policies substantially deviate away from the ideal blueprint and shift towards residential-dominant development. 


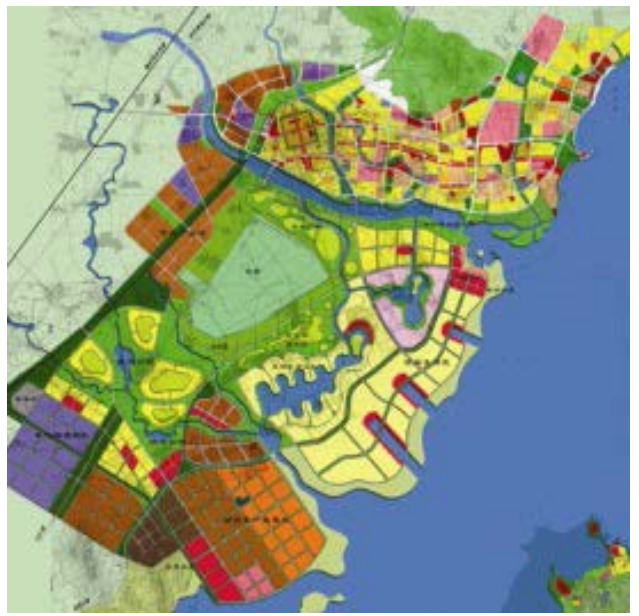

a) Xingcheng Coastal Industrial Area

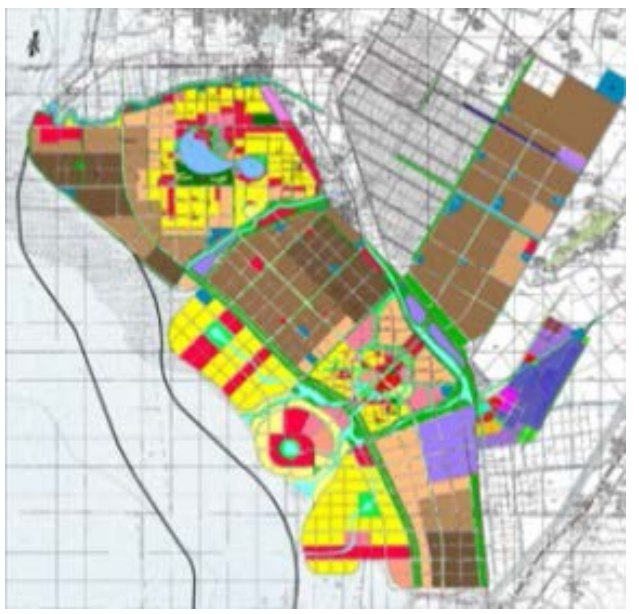

b) Yingkou Coastal Industrial Area

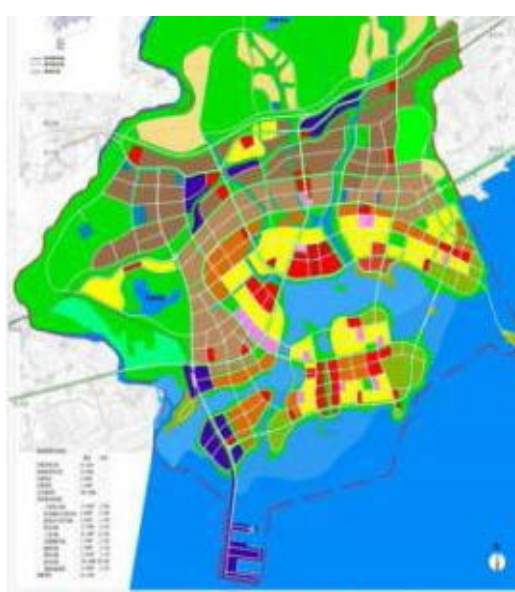

c) Huayuankou Economic Area

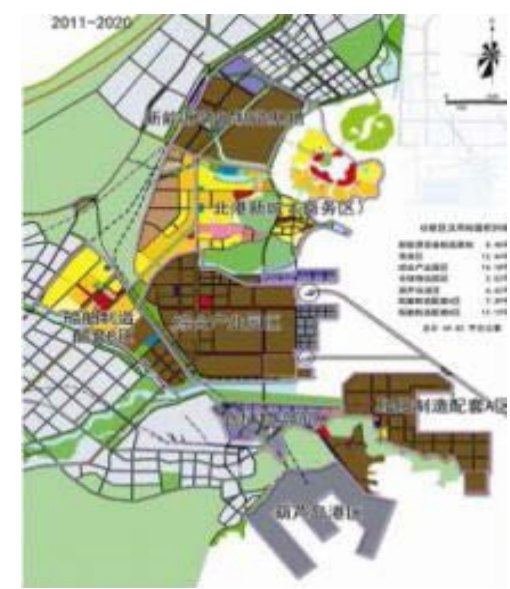

d) Huludao North Port Industrial Area

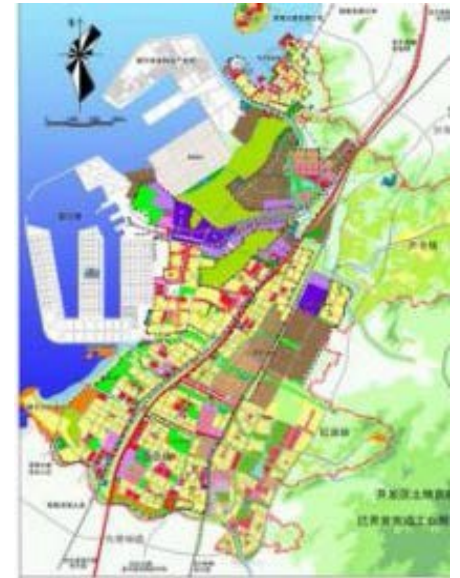

e) Bayuquan

Figure 6. Land distribution of selected MIDAs in Liaoning

Note. Data is obtained from GoogleEarth and manually labelled by the authors.

\subsection{Residential Land-Use and Urban Planning}

Two features related to residential land planning are identified. First, although away from metropolises, small but well-functioning towns surround MIDAs in Japan, South Korea and Singapore. However, Liaoning's MIDAs are too remotely located with no nearby towns or cities. Secondly, all MIDAs under study show clear separation between industrial and residential land, with visibly small land coverage for residential land use. In contrast, Liaoning's residential land area appears to be in similar or even greater scale than industrially zoned property, indicating over-development that could lead to low occupancy and ghost towns.

Residential land-use patterns vary slightly across Japan, South Korea and Singapore. Cases in Japan and South Korea show that residential areas are located inland near the industrial complex but separated by service land or designated green space. This segregation is designed to minimize the possibility of pollution (air, noise and water) that may affect the quality of life of surrounding citizens. The Puhang port has an alternative approach to maintain industrial-residential balance. With the production plants and shipping port located in the heart of Pohang, residential housings are located nearby on the two sides of the city and separated by river and greenspace. Convenient transportation has been established to facilitate short daily commute for workers while ensuring high-utilization of coastal land for industrial production. The case of Jurong Island in Singapore appears to be distinctive. Separated by only $10 \mathrm{~km}$ from the nearest city, no separate residential areas have been established. Convenient ground transportation allows worker to maintain city life while working for industrial 
complexes on the island.

Liaoning's MIDAs are uniquely planned with a close integration between residential and industrial land. The intention may have been to minimize commute time but could lead to serious concerns over pollution. In addition, no nearby towns or cities could be utilized to support residential life. In Table 2, column "distance from city center $(\mathrm{km})$ " presents the linear distance measured from the new areas to established city or town centers, with an average of $67.56 \mathrm{~km}$ for the nine cases we have examined. New towns have to be built from scratch to support tens of thousands of relocated employees. Provincial planning involves the construction of large residential complex with supporting public infrastructure and facilities, with the goal of establishing fully-functioning towns in a short horizon. The accompanied development of residential housing units should have allowed employees to minimize daily commute and maintain a healthy work-life balance. Service facilities such as hospitals, schools, local government buildings and other essential services were budgeted and constructed to improve the quality of life.

In our 2017 site visits, Bayuquan that began its development ten years ago still showed very little progress. Many public facilities such as schools and hospitals were still under construction. However, an upscale golf course recently opened near the steel plants occupying substantial landmass. Davis and Fung (2014) report on the empty and unfinished housing projects in Bayuquan, documenting at least two dozen 20-story abandoned apartment buildings and five years' worth of unsold apartments. The emergence of new "ghost cities" indicates a mismatch between planned infrastructure and residential necessities, which could seriously hinder the quality of life of industrial workers working at these MIDAs.

\section{Theoretical and Empirical Analyses}

The previous section studies the planning and land-use patterns of Liaoning's MIDAs in comparison to similar projects from neighboring countries. Large land mass, loosely integrated coastline, shipping ports and industrial plants, along with inadequate residential development have all contributed to the low industrial productivity in Liaoning. What are the driving forces behind these planning deficiencies? What are the planning goals and embedded challenges and potential conflicts? We first explore these questions qualitatively by adopting Campbell's planner's problem model. Subsequently, we follow up with an empirical assessment on the role of urban land governance and local government finances in shaping the developmental features of Liaoning's coastal projects.

\subsection{The Planner's Square-A Theoretical Approach}

Liaoning's MIDAs emerged from national, provincial and municipal strategic plans, with central planners assuming the vital role in project planning and facilitation. In his 1996 paper, Scott Campbell constructed an overarching model called the "planner's triangle", which examines three primary conflicts between the social, economic, and environmental aspects in pursuit of sustainable development (Campbell, 1996). This simple and visual framework attempts to identify the points of conflict and potential complementarities, and informs planners on their role as mediators in developing collaborative strategies to promote sustainable cities. Unique to Liaoning's case, central planners not only serve as mediators but have substantial power over resources allocation and project orientation. This characteristic enables us to dig further to examine whether the revealed planning deficiencies stemmed from unsolved conflicts.

Our interviews with local company managers, residents and workers discovered their rising concern over public health, which motivated us to extend the "planner's triangle" model (Figure 7a) to incorporate it as an additional planning priority to address five points of conflict ${ }^{6}$ beyond the original three (as shown in Figure $7 \mathrm{~b}$ ). We thereafter apply our "planner's square" model to coastal industrial projects in Liaoning and closely examine the main planning conflicts as well as the associated concerns and challenges. Lastly, we conclude with policy recommendations aiming to promote sustainable development.

Our model explores four planning priorities: economic development, environmental protection, social justice, and public health.

Economic Development: the model assumes that economic development is the primary objective of planners who view the economy as a marketplace to facilitate production and consumption. Economic growth relies on efficiency and innovation, and utilizes economic space to accommodate infrastructure, transportation and market needs.

Environmental protection: this is a complementary goal where planners treat the economy as a consumer of resources and a producer of wastes. Natural resources are scarce but essential to facilitate production, and ecological space requires careful planning to maintain its proper balance. 
Social justice: this planning priority promotes equitable distribution of resources, services and opportunities among different social groups with distinct needs.

Public health: manpower is the ultimate driver of economic progression and requires planners to properly establish the connection between urban planning and life-threatening diseases. Industrial pollution (air, noise and water) could lead to cardiovascular, respiratory and infectious diseases, while urban lifestyle changes may lead to mental health, obesity and other associated issues.

Stemmed from the four pillars of planning priorities, five prominent conflicts can be identified as shown in Figure $7 \mathrm{~b}$ and are analyzed in greater detail below.

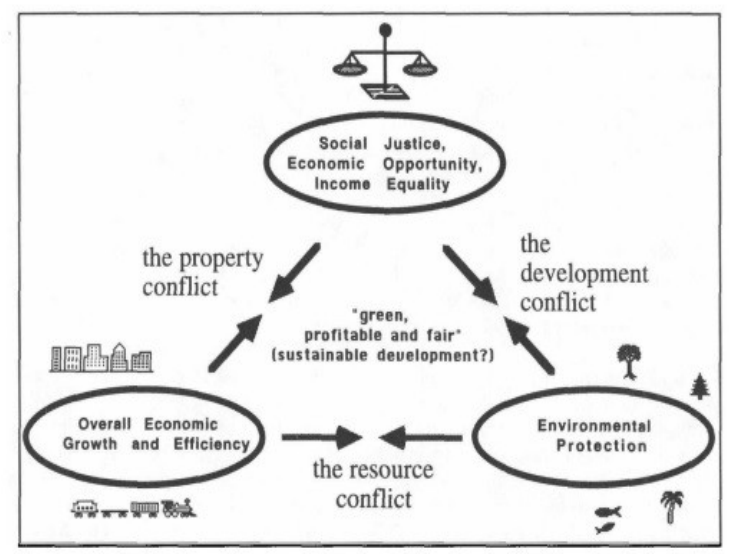

Figure 7a. Campbell's “planner's triangle"

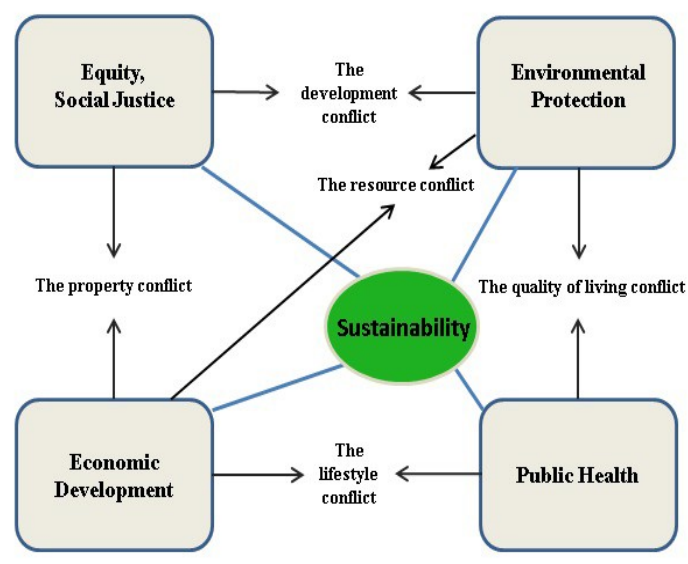

Figure $7 \mathrm{~b}$. The extended "planner's square" model

Note. The arrows characterize major points of conflict. Figure 7a is reproduced from Campbell (1996).

\subsubsection{The Property Conflict [Economic Development $\Leftrightarrow$ Social Justice]}

Consistent with the ideology put forth in Campbell (1996), the property conflict exists between economic development and social justice. As the economy strives for growth, there are competing claims on the use of land resources between different parties of interest. More specifically to our case study, there appears to be an increasing tension between industrial expansion and residential development as both compete for coastal frontage. The original planning objective of large-scale industrial development projects in costal Liaoning was to obtain convenient access to marine resources and enhance production efficiency. The significant landmass of these projects has been used as a major achievement by local government to promote their dedication and accomplishment towards economic development. However, the economic fundamentals mismatched the size of planning and the surplus oceanfront land sold to residential developers generates higher sales and tax revenue for the local government. Large-scale industrial and residential development typically involves relocation of long-time residents and may further distort social equity as the preference for building luxury (high-valued) residences limits housing affordability to low-income groups. In this case, the conflict between private interest and public goods is more prominent as local authorities endorse economic development as a planning priority.

Residential planning in Liaoning's MIDAs is notably leaning towards high-end and luxury lifestyle. Our site visits to Bayuquan in 2016 find high-rise apartment complexes with mostly three-bedroom units (with floor area around $90 \mathrm{~m}^{2}$ ) remain vacant. Local officials at the Bureau of Property Management in Yingkou reveal that the occupancy rate of residential dwellings at the industrial areas were only between $10 \%$ to $30 \%$. Due to China's one-child policy, most working families have three household members and commonly reside in one- or two-bedroom units. Since apartment complexes are sold on price per square meter, developers could generate greater revenue from larger units. Nonetheless, the employees in these industrial plants are mostly blue-collar, low to middle income groups that cannot afford expensive dwelling units, even with companies' relocation subsidy. Their housing residences in older cities before relocation were mostly provided at a low cost under the socialist planning era (before the 1999 housing reform), and are very small in size (less than $50 \mathrm{~m}^{2}$ ). In our interview with steel plant workers at Bayuquan, 20 out of 25 workers have established families in Yingkou (100km roundtrip) and commute regularly. 18 workers expressed that economic feasibility was the top reason for why they did not permanently relocate. Our further study of the central planning documents shows no indication 
of residential planning for low income groups or subsidized living, aggravating the conflict between economic development and social justice.

\subsubsection{The Resource Conflict [Economic Development $\Leftrightarrow$ Environmental Protection]}

The pursuit of economic development conflicts with natural resource preservation. The concept of economic-ecological conflict builds on the fundamental struggle between civilization and wilderness. Natural capital excavation allows mankind to develop modern, economically efficient, civilized living habitat but disorders the ecosystem by destructing landscapes, depleting fisheries, emitting greenhouse gases and producing harmful and toxic compounds. The fight for resources arises naturally as they are essential inputs to drive economic growth. Nonetheless, as economic development accelerates, climate change becomes inevitable and the associated high-cost natural disasters greatly distort social sustainability.

Resource allocation in Liaoning under central planning is beyond the demand at the local level and unsuitable for sustainable development. At Changxing Island Coastal Industrial Area, the gigantic landmass of $349.5 \mathrm{~km}^{2}$ fails to generate meaningful economic productivity for the region. It was established in 2005 as a national-level economic and technological development area, designed to facilitate major petrochemical production. Ten years after the initial construction, Dalian Statistical Yearbook reported that the gross product of Changxing amounts to RMB 10.2 billion in 2015, which was equivalent to about \$1.5 billion USD. Moreover, the total value of exported goods was reported to be $\$ 0.28$ billion USD, significantly below similar developments in Japan (i.e. Keiyo's total value of exports in 2009 was $\$ 68$ billion, yet occupying only $60 \mathrm{~km}^{2}$ of land).

The MIDAs not only occupy a significant industrial landmass, they also have ample residential buildings planned and constructed. The small-in-population residential towns consisted of a surplus of coastal residential land, high vacancy and many abandoned projects which have led to serious waste of resources. Instead of planning for essential needs such as public schools, hospitals, commercial districts and local recreational facilities, Liaoning focused on pioneering high-end public infrastructures. In Panjin's Liaodong Bay New Area, national-level sports stadium, upscale shopping malls, lavish art centers and sports complexes have been completed ahead of other supportive facilities. PGA level golf course adjacent to Bayuquan's steel plant also fails to support local residential needs. Massive land reclamation and degradation of coastal wetland in the case of Liaoning could lead to serious biodiversity loss and ecological imbalance. The two competing values need to be carefully incorporated in urban planning to allow human to have a long-term harmonious interaction with the nature, while promoting economic expansion to improve standards of living.

\subsubsection{The Development Conflict [Social Justice $\Leftrightarrow$ Environmental Protection]}

Environmental ethic conflict arises when protective policies become incompatible with social justice. In developing countries, environmental protection may limit economic growth and affect mostly the bottom of society, exacerbating wealth inequalities between rich and poor. Further, in resource-dependent communities such as our case of interest, some workers view environmental preservation as a roadblock to economic opportunities. More specifically, industrial productions in coastal Liaoning is heavily concentrated in oil, gas and petrochemical sectors, and high compliance cost to meet elevated pollution standards may result in compressed labor wage, non-wage benefits and other welfare to employees.

In addition, Liaoning's current adopted measures such as retaining large-scale greenspace in the city center for urban beautification and environmental protection purpose drastically limit the effective land supply in residential areas, leading to higher housing prices with detrimental effect to the working class. A local real estate developer in Liaodong Bay told us that the mandatory greenspace per dwelling unit requirement meant that they had to budget for $20 \%$ increase in areas from land reclamation, reduce the number of dwelling units by increasing the floor area per unit, and plan for multiple rooftop/balcony terraces per building to meet the government requirement. Although residential land appears to be abundant in contrast to cases from Japan, South Korea and Singapore, the property prices were still pushed up burdening the cost of planning deficiencies. Carbon tax on emission also raises energy price, once again challenging life affordability of low-income groups. Urban planners have to acknowledge that protecting the environment and delivering social justice may not always be compatible yet always indispensable to each other, which requires articulate policy design to establish a plausible middle ground.

\subsubsection{The Lifestyle Conflict [Economic Development $\Leftrightarrow$ Public Health]}

In general, economic growth is associated with greater income and subsequent higher health investments that improves public health conditions. The health of a population is critical to its sustainable development, and has inevitable effect on improving economic efficiency. Nonetheless, the connection between economic development 
and public health appears more complicated in the modern context. Planning conflict emerges as diseases triggered by obesity and sedentary lifestyles are tightly linked to urban planning and economic development. More specifically, China's rapid economic growth in the recent decades has sharply increased its obese population, leading to rampant cases of diabetes and other related chronic cardiovascular diseases (Zhang, 2015). Local authorities may initiate healthy living programs to encourage balanced lifestyles and formally incorporate obesity epidemic issues in public policy, but more importantly, urban planners have to consider public health as a primary planning objective in promoting sustainable development.

Another serious concern arising from our study is that industrial development along the coastlines of Liaoning further deteriorates public health conditions as massive relocation of production facilities to suburban areas resulted in extreme long-distance commute ( $>3$ hours) for employees on a daily basis. Dalian Petrochemical Company has 44 shuttle buses operating daily to transport nearly 2000 workers from the city of Dalian to Pine Island Industrial Park. The buses depart at 6:40am from Dalian and leave Pine Island at 4:30pm, with the average commuting time exceeding 100 minutes each way. Similar phenomenon is identified in both Panjin's Liaodong Bay and Yingkou's Bayuquan. Long commute presents serious challenge to the general health and living quality of employees. In the long-run, stressful commute may lead to both physical and mental health concerns and require local planners to adopt effective measures to rebuild healthy lifestyles. Nie and Souza-Poza (2016) categorize commute time of more than one hour daily to be "extreme", which is found to be associated with lower levels of life satisfaction and happiness in the long-run. The long commute time also suppresses family leisure time, aggravates family separation and hinders happiness and life satisfaction. Furthermore, some of major real estate development projects have been abandoned after years of low sale and lack of infrastructural support.

\subsubsection{The Quality of Living [Public Health $\Leftrightarrow$ Environmental Protection]}

Environmental protection is essential to shield the society from negative externalities of industrialization. Policies that control air, noise and water pollution would reduce associated respiratory and infectious diseases, but the healthcare system itself is energy-intensive and a major emitter of pollution (Eckelman and Sherman, 2016). Another conflict arises from measures adopted to improve public health that could undermine environmental protection. For example, to control the widespread of mosquito-borne viruses such as malaria, ZIKA and west nile, heavy use of chemical pesticides (DDT especially) may also destruct pollinators and subsequently cause adverse ecological distortions.

One of the planning objectives of the large-scale relocation of industrial plants from inland to coastal areas in Liaoning was to effectively use marine resources to control for pollution. The remote location and inadequate support for local living forced many employees to continue long-term commute that causes mental and physical destruction. In addition, the relocation has resulted in other environmental disruptions to local fisheries, natural habitats and other species. Newly developed residential towns also face shortages of public goods such as emergency medical centers, specialized hospital facilities and professional therapy services. In Bayuquan and Liaodong Bay, large-scale town squares were constructed to allow residents to engage in daily exercise, square dancing (popular group activity in China), and other recreational activities. Aimed at promoting public health through physical exercise, these well-designed, showcase level town squares involved significant farm land conversion and hinders environmental balance. Pesticides have to be applied to local ponds and greenspace to maintain beautification, which could affect public health.

The paradox is further embedded in land zoning and planning. To promote a better work-life balance and reduce commute time, many residential properties are planned with great proximity to the industrial plants with no visible separation by greenspace or non-industrial land (Figure 6b, c, and d). Excessive air and noise pollution from petrochemical plants lead to serious health concerns for local residents. In August 2016, we have conducted a random street interview near a residential complex located at Yingkou's Bayuquan industrial area, asking general questions about the residents' quality of living. Out of 12 residents interviewed, 10 have expressed a change of air quality since the completion of the adjacent steel plants (500 meters away). Ocean breeze carried dust and haze to their dwelling units, even preventing them from opening any window. Workers also have to wear facemasks to work to avoid inhaling excessive dust. This could also help to explain why workers were reluctant to relocate to the new plants and the emergence of the ghost towns. Although environmental protection and public health policies are commonly perceived to go hand-in-hand and mutually reinforcing, planners have to be more cautious to find ways to mediate and resolve rising conflicts between the two values.

\subsection{Descriptive and Econometric Analysis}

Our theoretical analysis reveals five planning conflicts in Liaoning's MIDAs but we are still puzzled by how 
these conflicts emerged and remained unresolved in light of failing economic performances and rising social tensions. Our interview with local town officials pointed us to land governance and the economic incentives behind excessive residential development. Our hypothesis is that the declining economic trends in Liaoning added fiscal pressure to local governments who resorted to land sales and real estate tax as supplementary incomes. Empirical analysis supports the claim and concludes that real estate investments are tightly linked to local fiscal revenue at the city level. Lastly, purchase restrictions and real estate market speculation served as catalytic role in driving up the demand for real estate investments.

\subsubsection{Economic Trends in Local Fiscal Condition}

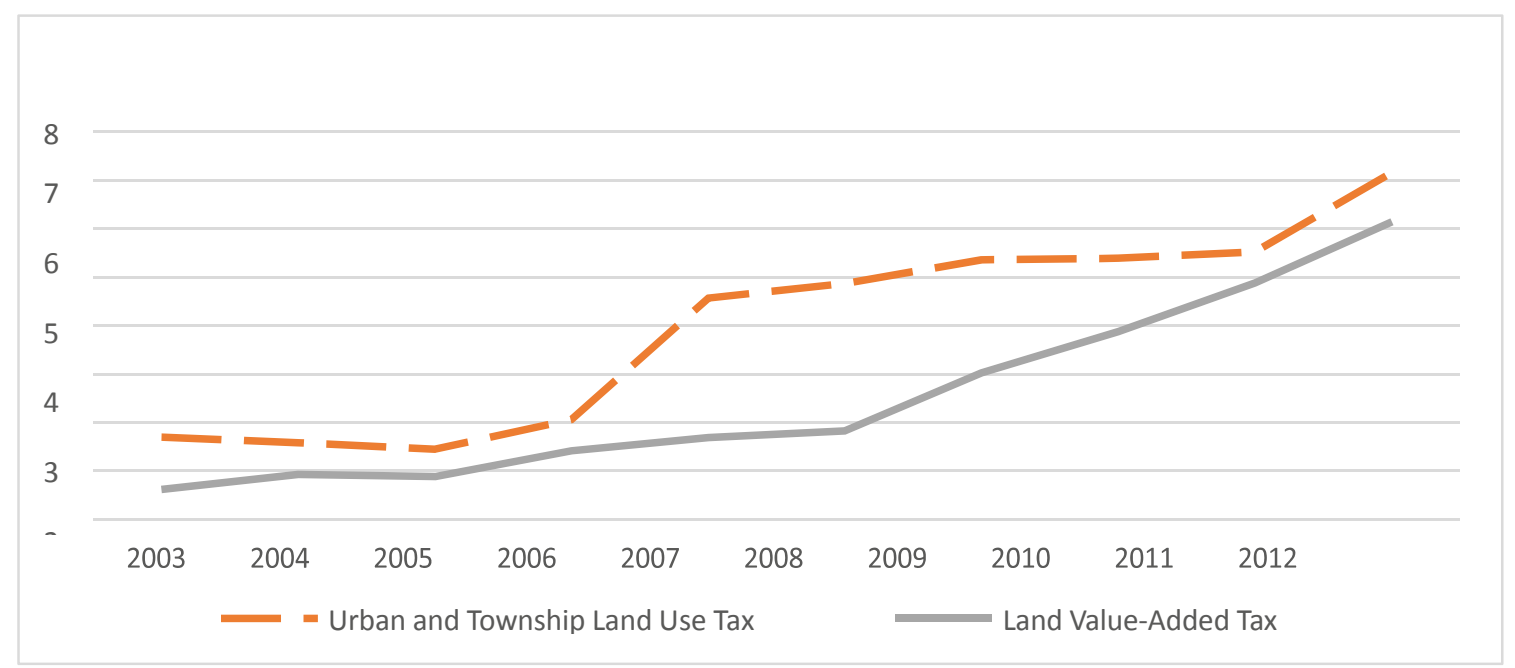

Figure 8. Proportions of land use tax and land value-added tax in Liaoning (2003-2012)

Note. Data is obtained from Liaoning Statistical Yearbook (2002-2013)

China has initiated a series of fiscal reform since 1994 that divided central and local administrative powers, and granted up to $75 \%$ of VAT to be replenished to the central government. Local government has since relied heavily on land financing, land leasing fees and transfer fees to fund local economic growth. Figure 8 shows Liaoning's urban/township land use tax and land value-added tax as a percentage of total fiscal revenue from 2003 to 2012. Urban and township land-use tax (LUT) involves a broad tax base that includes all domestic enterprises, work units, individuals and household businesses, and collected on the basis of actual size of land occupied. Land value-added tax (LVT) is collected on taxpayers' income derived from transference of use rights of state-owned land and property rights of buildings. It is evident from the data that the proportion of both taxes in Liaoning's fiscal revenue have increased significantly over the past decade. In 2003, LUT and LVT are reported to respectively account for $1.69 \%$ and $0.62 \%$ of the provincial fiscal revenue, but grew to respectively 7.16\% and 6.14\% in 2012. Dong and Wang (2016) report that government running consistent fiscal deficits sold more land to finance budgetary operations, and rely more extensively on real estate conditions to finance economic projects. Liaoning has been running a fiscal deficit since the late 1990s and since relied substantially on government loans and real estate income to finance government investments. The proportion of land-related tax in total fiscal revenue has increased significantly since 2003, along with deteriorating fiscal income (fiscal revenue net of fiscal expenses) evidently shown in Figure 9. In addition, land sales for residential and commercial real estate development has also increased substantially from RMB 3.47 billion in 2000 to 52.26 billion in 2011. Persistent debt and worsening economic conditions provide increasing incentives for the provincial government to promote land sales and real estate development, which may have been a leading factor for the residential-dominant development. 


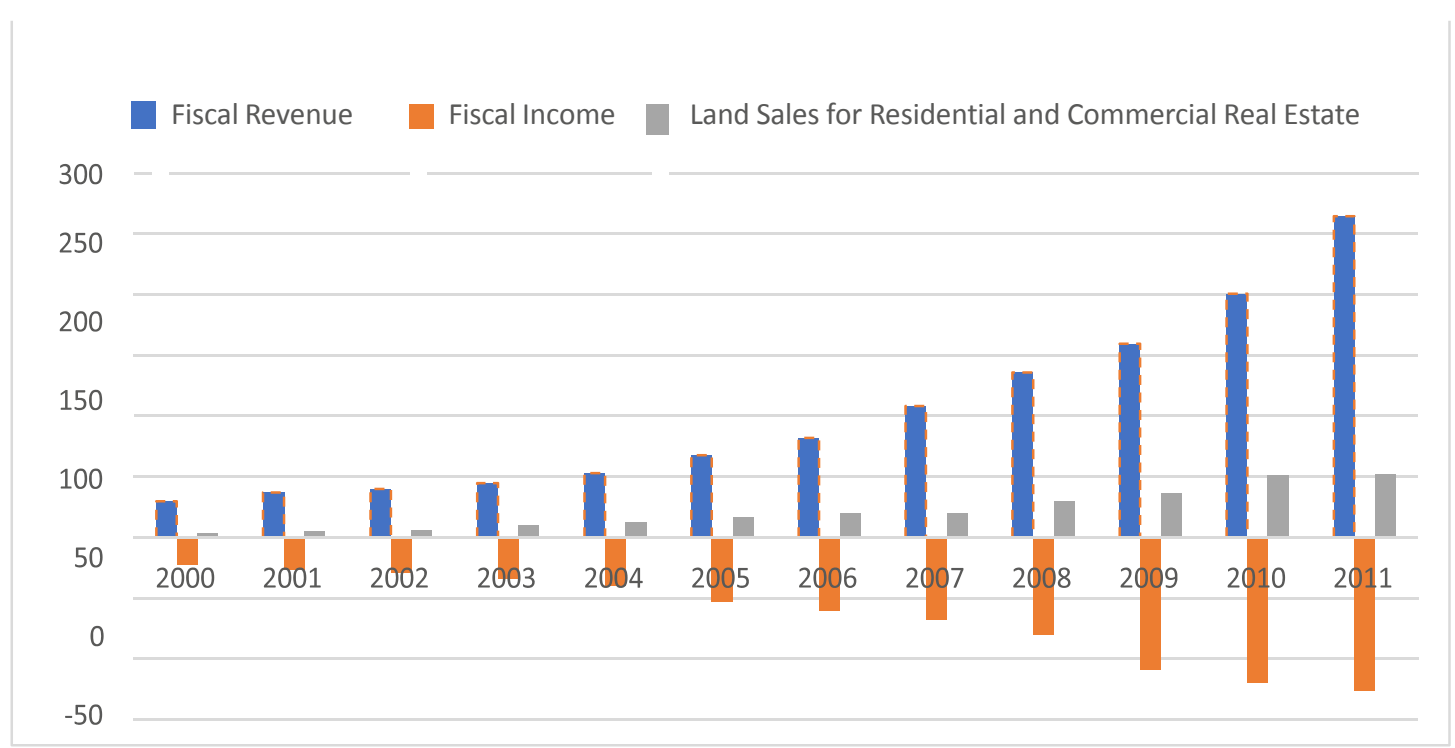

Figure 9. Fiscal revenue, fiscal income and land sales for residential and commercial real estate

Note. Data is obtained from Liaoning Statistical Yearbook (1999-2012)

\subsubsection{Granger Causality Tests}

Visibly from Figures 9 and 10, there has been an increasing trend in both land tax as a percentage of total fiscal revenue, as well as the proceeds from land sales for residential and commercial real estate. In this section, we focus on the exact relationship between local real estate investments and fiscal revenue, and find a significant separation between coastal and non-coastal cities. Using a panel of all 14 cities in Liaoning, spanning from 1995 to 2015, we test for one-way, two-way or no short-term causality in either direction. We explore the short-run dynamic bivariate panel causality between real estate investments and fiscal revenue, following a simple approach proposed by Dumitrescu and Hurlin (2012). This test builds upon the fixed coefficients in a VAR framework using stationary data, and takes account of two dimensions of heterogeneity: the heterogeneity of the regression model used to test the Granger causality and the heterogeneity of the causality relationships. The Wald statistics for testing Granger non-causality are computed for the overall panel, and two subpanels separating coastal and non-coastal cities. Among the 14 cities, 6 are coastal cities (Dalian, Dandong, Huludao, Jinzhou, Panjin, and Yingkou), and 8 are non-coastal cities (Shenyang [the provincial capital], Anshan, Benxi, Chaoyang, Fushun, Fuxin, Liaoyang, and Tieling).

Our data on real estate investment and fiscal revenue is obtained from the Statistical Yearbook (1995-2015) of each city in Liaoning, and Table 3 reports the summary statistics for our panel and subpanels. All data is seasonally adjusted using X-ARIMA 11 and natural logarithms are taken and denoted by $\operatorname{lnFR}$ (fiscal revenue) and lnRI (real estate investments). To employ the heterogeneous Granger causality test, we must ensure stationarity for the whole province panel, as well as for the coastal and non-coastal subpanel. We employ three unit root tests including Levin, Lin, and Chu (LLC) (2002), Im, Pesaran, and Shin (IPS) (1997), and the classic Fisher Augmented Dickey-Fuller (Fisher-ADF) test. Lags are selected using the Akaike Information Criterion (AIC) with a maximum lag of 4 . Detailed results and p-values are reported in Table 4.

Since all three test results suggest that real estate investment and fiscal revenue are I(1) stationary at the $1 \%$ significance level, we hereby use first differences to implement the Granger causality test. Table 5 provides the panel Granger test results (standardized Z statistics) for the whole panel and two subpanels. For the whole province panel, both null hypotheses are rejected and the results depict a significant two-way causality effect between changes in fiscal revenue and real estate investments. Improvement in fiscal conditions promote real estate development, meanwhile, investments in commercial and residential real estate imply greater property-related taxes that contribute positively to fiscal revenue. Nonetheless, the subpanel results appear more interesting. For the six coastal cities understudy, the two-way causality effect is similar to the whole panel. Both the null hypotheses that changes in fiscal revenue do not Granger cause changes in real estate investment, as well as changes in real estate investment do not Granger cause changes in fiscal revenue, are respectively rejected at the $1 \%$ and $5 \%$ significance level. 
Table 3. Summary statistics

\begin{tabular}{cccc}
\hline Variable & Whole Province & Coastal Cities & Non-coastal Cities \\
\hline 1. Fiscal Revenue (millions & & & \\
of RMB) & & & \\
Mean & 11781.96 & 6256.90 & 5594.16 \\
Standard Deviation & 5878.19 & 12299.92 & 11407.01 \\
Maximum & 70173.18 & 66840.02 & 70173.18 \\
Minimum & 143.75 & 142.75 & 160.47 \\
Observations & 294 & 126 & 168 \\
2. Real Estate Investment & & & \\
(millions of RMB) & & & 11943.30 \\
Mean & 30207.85 & 11134.60 & 33830.63 \\
Standard Deviation & 11596.71 & 24687.83 & 217891.90 \\
Maximum & 217891.90 & 154649.60 & 60.01 \\
Minimum & 60.01 & 67.40 & 168 \\
Observations & 294 & 126 &
\end{tabular}

Note. Data is obtained from Statistical Yearbook of Shenyang, Anshan, Benxi, Chaoyang, Dalian, Dandong, Fushun, Fuxin, Huludao, Jinzhou, Liaoyang, Panjin, Tieling and Yingkou (1995 - 2015).

Table 4. Panel unit root test results

\begin{tabular}{ccccc}
\hline Variable & Method & Whole Province & Coastal Cities & Non-coastal Cities \\
\hline LnFR & LLC & $0.000^{* * *}$ & $0.000^{* * *}$ & $0.000^{* * *}$ \\
& IPS & $0.022^{* *}$ & $0.052^{*}$ & 0.103 \\
& Fisher-ADF & $0.014^{* *}$ & $0.048^{* *}$ & $0.058^{*}$ \\
\multirow{3}{*}{$\Delta \operatorname{lnFR}$} & LLC & $0.000^{* * *}$ & $0.005^{* * *}$ & $0.001^{* * *}$ \\
& IPS & $0.000^{* * *}$ & $0.003^{* * *}$ & $0.001 * * *$ \\
& Fisher-ADF & $0.000^{* * *}$ & $0.002^{* * *}$ & $0.000^{* * *}$ \\
\multirow{2}{*}{ LnRI } & LLC & $0.007 * * *$ & $0.029^{* *}$ & $0.054^{*}$ \\
& IPS & 0.934 & 0.816 & 0.887 \\
& Fisher-ADF & 0.982 & 0.859 & 0.959 \\
& LLC & $0.000^{* * *}$ & $0.001 * * *$ & $0.000^{* * *}$ \\
& IPS & $0.000^{* * *}$ & $0.000^{* * *}$ & $0.000^{* * *}$ \\
& Fisher-ADF & $0.000^{* * *}$ & $0.000^{* * *}$ & $0.000^{* * *}$ \\
\hline
\end{tabular}

Note. $\Delta$ denotes the first order difference. ${ }^{*}, * *$, and $* * *$ respectively represent rejections of the null at the $1 \%, 5 \%$ and $10 \%$ significance level.

This is consistent with our previous conjecture that fiscal conditions in coastal cities are tightly connected to real estate activities, which provides local government with the incentive to initiate large-scale coastal industrial expansion to subsequently promote commercial and residential land development. In contrast, non-coastal cities exhibit a loose link between real estate investment and fiscal revenue. The non-coastal subpanel weakly rejects the first null hypothesis that changes in fiscal revenue do not Granger cause changes in real estate investment, at the $10 \%$ significance level. Furthermore, the test fails to reject the second null hypothesis that changes in real estate investment do not Granger cause changes in fiscal revenue. This finding implies that real estate development in non-coastal has a weak causal effect on fiscal conditions, which may mean less incentive for land development at a massive level. 


\subsubsection{Investment Condition and Market Speculation}

China's housing market has sustained double-digit growth in average prices over the past decade, with some cities like Beijing and Shanghai experiencing more than 500\% growth since 2003. To prevent potential bubbles and crises, the national government has initiated a series of housing purchase restrictions since 2010. For example, a "one-unit-per-household" policy has been administered in Dalian in 2010 limiting each household to purchase only one residential dwelling unit. For owners with more than one unit, the down payment requirement for the primary residence has increased to $30 \%$, and $50 \%$ for the second housing unit. Lending for the third and more residential units has ceased altogether. Nonetheless, local governments were given some flexibility in administering purchase restriction policies and often excluded new economic development areas. In Dalian, the purchase restrictions were placed on urban residences only and largely excluded the Pine Island and Changxing Island coastal development areas. Investment demand and market speculation surged in these newly developed coastal areas and resulted in a sharp increase in new dwelling units constructed. Due to the lack of economic fundamentals and slow industrial growth, many residential projects have been abandoned and become unoccupied. Monetary tightening in 2015 has also added financial strains on real estate developers leading to construction delay and abandonment. News report of "ghost cities" in suburban areas of Dalian, Panjin and Yingkou have appeared since 2014, which was associated with a significant loss of economic efficiency and productivity as many of these developments occupy quality coastal land preventing industrial plants to access valuable marine resources.

Table 5. Panel granger causality test results

\begin{tabular}{cccc}
\hline Null Hypothesis & Whole Province & Coastal Cities & Non-Coastal Cities \\
\hline $\begin{array}{c}\Delta \operatorname{lnFR} \text { does not Granger cause } \\
\Delta \operatorname{lnRI}\end{array}$ & $0.003^{* * *}$ & $0.005^{* * *}$ & $0.062^{*}$ \\
$\begin{array}{c}\Delta \operatorname{lnRI} \text { does not Granger cause } \\
\Delta \operatorname{lnFR}\end{array}$ & $0.005^{* * *}$ & $0.012^{* *}$ & 0.218 \\
\hline
\end{tabular}

Note. $\Delta$ denotes the first order difference. ${ }^{*},{ }^{*}$, and ${ }^{* * *}$ respectively represent rejections of the null at the $1 \%, 5 \%$ and $10 \%$ significance level.

\section{Discussion}

Our paper investigates a series of recent large-scale coastal industrial development projects in Liaoning, China, and analyzes the land-use pattern, industrial-residential balance, as well as economic activities and urban land development. We adopt a case study methodology to compare MIDAs in Japan, South Korea and Singapore, and find that similar projects in Liaoning have 1) much greater landmass and coverage; 2) high level of segregation between production plants and shipping port leading to low production efficiency; 3) shown prevalent characteristics of residential-dominant land development, possibly due to tight link to local government fiscal revenue; and 4) exhibited early signs of the emergence of "ghost cities" in newly established residential areas. Our theoretical research contributes to identification of prominent issues and planning conflicts in Liaoning's coastal projects. Continued research is required to investigate the possible issue of over-supply in residential housing units and the inefficient use of prime coastal resources for industrial purposes.

We further conduct econometric analysis to examine the two-way causality relationship between local government fiscal revenue and real estate development. Using the panel Granger causality test approach, our results show that the two-way Granger causality is present in the whole-province panel of 14 cities, but there exists some coastal and non-costal separation in the relationship. More specifically, we confirm the presence of the two-way causality relationship for the subpanel of six coastal cities but could only weakly reject the null of changes of fiscal revenue do not Granger cause changes in real estate investment in non-coastal cities.

The role of urban planners also extends far beyond that of a mediator, but an innovative pioneer in guiding the society to become a greener, healthier, more advanced yet equitable built environment. We advise that planning authorities in Liaoning need to work closely with the local communities to first enhance public infrastructures of the newly-developed residential towns, expand service and supportive sectors to enhance the quality of living for relocated residents. Moreover, residential projects in planning stage must be carefully reviewed to avoid formation of "ghost towns" and provide sufficient affordable housing units to low-income families. In addition, industrial production requires increased integration to marine resources to improve efficiency and environmental 
preservation. Large-scale land reclamation projects in planning stage must also be critically assessed with respect to economic feasibility and potential ecological impact. The cooperation of authorities, environmental activists, enterprises and local residents is essential to promote sustainable development in the long-run.

\section{Acknowledgments}

This paper is supported by the China National Natural Science Foundation [No. 51778099, No. 51608089].

\section{References}

Berke, P. (2016). Twenty years after Campbell's vision: have we achieved more sustainable cities? Journal of the American Planning Association, 82(4), 380-382. https://doi.org/10.1080/01944363.2016.1214539

Campbell, S. D. (1996). Green cities, growing cities, just cities? Urban planning and the contradictions of sustainable development. Journal of the American Planning Association, 62(3), 296-312. https://doi.org/10.1080/01944369608975696

Campbell, S. D. (2016). The planner's triangle revisited: sustainability and the evolution of a planning ideal that can't stand still. Journal of the American Planning Association, 82(4), 388-397. https://doi.org/10.1080/01944363.2016.1214080

Chen, B., \& Feng, Y. (2000). Determinants of economic growth in China: Private enterprise, education, and openness. China Economic Review, 11(1), 1-15. https://doi.org/10.1016/S1043-951X(99)00014-0

Chen, M., Liu, W., \& Lu, D. (2016). Challenges and the way forward in China's new-type urbanization. Land Use Policy, 55, 334-339. https://doi.org/10.1016/j.landusepol.2015.07.025

Davis, B., \& Fung, E. (2014, April 15). This Chinese City's Property Market Is Even Chillier Than Its-22-Degree Weather. Wall Street Journal. Retrieved October 1, 2017, from http://on.wsj.com/1qXqnRY

Ding, C. (2003). Land policy reform in China: assessment and prospects. Land Use Policy, 20(2), 109-120. https://doi.org/10.1016/S0264-8377(02)00073-X

Dong, G. N., \& Wang, Z. (2017). House price, land sales and local government finance in developing economies: evidence from China. Manuscript. Columbia University.

Dumitrescu, E., \& Hurlin, C. (2012). Testing for Granger non-causality in heterogeneous panels. Economic Modelling, 29(4), 1450-1460. https://doi.org/10.1016/j.econmod.2012.02.014

Eckelman, M. J., \& Sherman, J. (2016). Environmental Impacts of the U.S. Health Care System and Effects on Public Health. PLoS ONE, 11(6), e0157014. https://doi.org/10.1371/journal.pone.0157014

Han, S. S., \& Yan, Z. (1999). China's coastal cities: development, planning and challenges. Habitat International, 23(2), 217-229. https://doi.org/10.1016/S0197-3975(98)00046-0

He, S. J., \& Wu, F. (2005). Property-led redevelopment in post-reform China: A case study of Xintiandi redevelopment project in Shanghai. Journal of Urban Affairs, 27(1), 1-23. https://doi.org/10.1111/j.0735-2166.2005.00222.x

Hsing, Y. (2006). Land and territorial politics in urban China. The China Quarterly, 187, 575-591. https://doi.org/10.1017/S0305741006000385

Hsing, Y. (2010). The great urban transformation: Politics of land and property in China. Oxford, UK: Oxford University Press. https://doi.org/10.1093/acprof:oso/9780199568048.001.0001

Im, K. S., Pesaran, M., \& Shin, Y. (2003). Testing for unit roots in heterogeneous panels. Journal of Econmetrics, 115(1), 53-74. https://doi.org/10.1016/S0304-4076(03)00092-7

Jin, X., Long, Y., Sun, W., Lu, Y., Yang, X., \& Tang, J. (2017). Evaluating cities vitality and identifying ghost cities in China with emerging geographical data. Cities, 63, 98-109. https://doi.org/10.1016/j.cities.2017.01.002

Levin, A., Lin, C. F., \& Chu, C. S. J. (2002). Unit root tests in panel data: asymptotic and finite-sample properties. Journal of Econometrics, 108(1), 1-24. https://doi.org/10.1016/S0304-4076(01)00098-7

Lichtenberg, E., \& Ding, C. (2009). Local officials as land developers: Urban spatial expansion in China. Journal of Urban Economics, 66(1), 57-64. https://doi.org/10.1016/j.jue.2009.03.002

Lin, G. C., \& Yi, F. (2011). Urbanization of Capital or Capitalization on Urban Land? Land Development and Local Public Finance in Urbanizing China. Urban Geography, 32(1), 50-79. https://doi.org/10.2747/0272-3638.32.1.50

Liu, H., Jin, F., \& Liu, Y. (2012). Research on the evolution and mechanism of spatial organization of 
petrochemical industry in China. Geographical Research, 31(11), 2031-2043.

Liu, Y. (2007). Rural transformation development and new countryside construction in Eastern Coastal Area of China. Acta Geographica Sinica, 62(1), 563-570.

Lu, Y., \& Sun, T. (2013). Local governments financing platforms in China: a fortune or a misfortune? IMF Working Paper, WP/13/243.

Ma, W., Wu, C., Yin, S., \& Liu, Y. (2014). Analysis on Change of Coastline and Reclamation in Liaoning Province. Environment and Sustainable Development, June, 54-57.

Mody, A., \& Wang, F. (1997). Explaining Industrial Growth in Coastal China: Economic Reforms ... and What Else? The World Bank Economic Review, 11(2), 293-325. https://doi.org/10.1093/wber/11.2.293

Moreno, E. L., \& Blanco, Z. G. (2014). Ghost cities and empty houses: wasted prosperity. American International Journal of Social Science, 3(2), 207-216.

Nie, P., \& Sousa-Poza, A. (2016). Commute time and subjective well-being in urban China. China Economic Review.

Ren, W., Wang, Q., \& Ji, J. (2018). Research on China's Marine Economic Growth Pattern: An Empirical Analysis of China's Eleven Coastal Regions. Marine Policy, 87, 158-166. https://doi.org/10.1016/j.marpol.2017.10.021

Robinson, R. (1985). Industrial strategies and port development in developing countries: The Asian case.

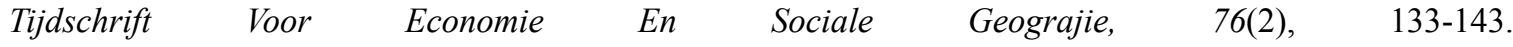
https://doi.org/10.1111/j.1467-9663.1985.tb01614.x

Song, G., Feng, R., \& Li, Z. (2017). Research on the development paths of coastal port logistics industry of Liaoning under the background of new normal (in Chinese). Logistics Engineering and Management, 39(2), 9-12.

Sonn, J. (2005). Regionally embedded spatial autonomy: The spatial process of the developmental state in South Korea, 1970s. Research Papers in Environmental and Spatial Analysis Series, 110, 1-39.

Sorace, C., \& Hurst, W. (2015). China's phantom urbanisation and the pathology of ghost cities. Journal of Contemporary Asia, 46(2), 304-322. https://doi.org/10.1080/00472336.2015.1115532

Todd, D., \& Hsueh, Y. C. (1990). New port developments and balanced regional growth: A Taiwan example. Geoforum, 21(4), 421-433. https://doi.org/10.1016/0016-7185(90)90022-X

Wang, H., Chen, T., \& Ma, H. (2018). Different institutions, distinctive trajectories? Revisiting maritime industrial development areas with cases on China's Liaoning coast. Growth and Change, 49(1), 165-188. https://doi.org/10.1111/grow.12230

Wang, W., Liu, H., Li, Y., \& Su, J. (2014). Development and management of land reclamation in China. Ocean and Coastal Management, 102, 415-425. https://doi.org/10.1016/j.ocecoaman.2014.03.009

$\mathrm{Wu}, \mathrm{F} ., \mathrm{Xu}, \mathrm{J} .$, \& Yeh, A. (2007). Urban development in post-reform China: State, market, and space. London, UK: Routledge.

Xu, J., \& Yeh, A. (2009). Decoding urban land governance: State reconstruction in contemporary Chinese cities. Urban Studies, 46(3), 559-581. https://doi.org/10.1177/0042098008100995

Yu, H. (2014). Chinas "ghost cities". East Asian Policy, 6(02), 33-43. https://doi.org/10.1142/S1793930514000142

Zhang, L., Legates, R., \& Zhao, M. (2016). Understanding China's urbanization: The great demographic, spatial, economic, and social transformation. Cheltenham, UK: Edward Elgar. https://doi.org/10.4337/9781783474745

Zhang, S. (2014). Land-centered urban politics in transitional China - Can they be explained by growth machine theory? Cities, 41, 179-186. https://doi.org/10.1016/j.cities.2014.02.010

Zhang, T. (2017). The effects of economic development and built environment on diabetes in China. Population Health Metrics, 15-35. https://doi.org/10.1186/s12963-017-0152-2

\section{Notes}

Note 1 . See Chapter 9 and 14 of China's $12^{\text {th }}$ Five-Year Plan, translated version by the Delegation of the 
European Union in China can be accessed from

https://cbi.typepad.com/files/full-translation-5-yr-plan-2011-2015.doc

Note 2. For example, in National Major Functional Zoning Plan (2010), it states that "coastal cities develop port-oriented industries, and promote development in port cities". "Major projects that mostly utilize imported resources should primarily be planned to locate in coastal regions" appeared in both the $12^{\text {th }}$ Five-Year Plan for Economic and Social Development (2011) and Planning for Transformation and Upgrading of Industries (2011). Blueprint for the Adjustment and Revitalization of the Steel Industry (2009) states that "the production capacity of steel plants located in coastal (both ocean and freshwater) areas account for more than $40 \%$ of the national production capacity".

Note 3. See Vigarie (1981), Dunford and Yeung (2009), Vallega (2001) and Wang (2014) for an overview on the historical development of MIDAs around the world.

Note 4. See Yu (2014), Sorace and Hurst (2015), Chen et al. (2016), Jin et al. (2017) and Moreno and Blanco (2014) for a few exemplary works.

Note 5. These MIDAs largely emerged from nation-wide planning aimed to expand industrial production and economic growth locally. See for example Japan's Law of Port (1955), Comprehensive National Development Plan Act (1950), First Plan (1962) and Second Plan (1969); and South Korea's Comprehensive National Land Planning Act (1962).

Note 6 . The conflict between public health and equity may exist on a philosophical perspective but is beyond consideration in our case study, and hence will not be further discussed here.

\section{Copyrights}

Copyright for this article is retained by the author(s), with first publication rights granted to the journal.

This is an open-access article distributed under the terms and conditions of the Creative Commons Attribution license (http://creativecommons.org/licenses/by/4.0/). 